九州大学学術情報リポジトリ

Kyushu University Institutional Repository

\title{
Fabrication of a Lotus-type Porous Material to be Applied in Heat Pipe Wick
}

Supriadi, S.

Departement of Mechanical Engineering, Universitas Indonesia

Putra, N.

Departement of Mechanical Engineering, Universitas Indonesia

Ariantara, B.

Departement of Mechanical Engineering, Universitas Indonesia

Indhiarto, I.

Departement of Mechanical Engineering, Universitas Indonesia

https://doi.org/10.5109/4742132

出版情報：Evergreen. 8 (4)，pp.855-860，2021-12. 九州大学グリーンテクノロジー研究教育センター バージョン：

権利関係 : 


\title{
Fabrication of a Lotus-type Porous Material to be Applied in Heat Pipe Wick
}

\author{
S. Supriadi*, N. Putra, B. Ariantara, I. Indhiarto \\ Department of Mechanical Engineering, Universitas Indonesia, Depok 16424, Indonesia
}

*Corresponding Author’s email: sugeng@eng.ui.ac.id

(Received April 30, 2021; Revised December 16, 2021; accepted December 16, 2021).

\begin{abstract}
There are high demands on a state of the art technology in the field of heat pipes, especially in capillary pumping performance. Previous studies concluded that a biomaterial had a superior performance as a material for the capillary wick. However, it was followed by consequences of harnessing the ecosystem. A new material that mimics a lotus stem and exceeds the performance of a coral will be a necessity. It is projected that Lotus-Type Porous Material (LTP) can outperform a coral performance as wick material. The lotus-type porous material was fabricated with a slip casting process using a starch binder and copper powder. A nylon wire was employed as the aligned pore former. To remove moisture after the slip casting process, we used a freeze-drying technique. Densification and consolidation of copper powder were carried out with the sintering process. The performance of the lotus-type porous material was characterized in order to get a capillary pumping coefficient. We analyzed the pore using an SEM and X-ray 3D Scan. The result showed that an excellent capillary pumping performance could be achieved using the lotus-type porous material. We also confirmed these phenomena using an SEM and xray $3 \mathrm{D}$ scan analysis. It is concluded that lotus-type porous material performs excellent fluid transport capability.
\end{abstract}

Keywords: Lotus type porous material; Heat pipe; Wick material; Sintering

\section{Introduction and background}

Cooling technology is necessary for high energy consumption. Therefore free energy cooling system will give significant benefits for energy efficiency ${ }^{1)}$. Low energy consumption in cooling systems also has been developed based on dehumidification in agriculture ${ }^{2)}$. The improvement was also conducted by applying honeycomb desiccant block ${ }^{3}$. Another passive cooling technique is using heat pipes without consuming energy. Heat pipes have high thermal conductivity; accordingly, they have been used in various thermal exchanging applications. A typical heat pipe consists of a capillary wick pipe and working fluid. Capillary wick rely on the capillary performance of the material because of its geometry. A biomaterial has been introduced as a base material for building capillary wick. Coral is used as a biomaterial since its high porosity can enhance the capillary performance of the capillary wick ${ }^{4,5)}$. The porosity of the coral tabulates used in that experiment had a $30.15 \%$ porosity and a $5.10^{-15} \mathrm{~m}^{2}$ permeability ${ }^{4)}$. The real-time performance of the heat pipe was determined by three main parameters; gas reservoir volume, pore structure, and cooling fluid ${ }^{6}$. Several research on heat pipe has been conducted by applying nanoparticle to cooling fluid in the heatpipe $^{7-9}$. Application of the heat pipe also has been observed in tea drying using geothermal energy and development of passive cooling for battery and an electric motor in electric vehicle ${ }^{10,11)}$.

Thermal performance from a capillary wick with sintered powder had more advantages than that of the screen-mesh configuration ${ }^{12}$. The experiment used $\mathrm{CuO}$ nanofluids as its working fluid ${ }^{12)}$. The results of the experiment showed that the sintered powder had 14,3\% more heat transport capacity than that of the screen-mesh under the same operating condition ${ }^{13)}$. Experimental studies generally concluded that a capillary wick with a groove configuration was affected very much by the gravitational forces. We made this in the specific application engaged with the gravity that will be less efficient than that of the sintered powder. In the inverted $\mathrm{U}$ orientation, the groove capillary wick had a significantly higher thermal resistance than the sintered powder. From those studies, sintered copper has been explored to enhance heat transfer capability ${ }^{14)}$. It is fabricated with powder metallurgy technique using $\mathrm{NaCl}$ pore former ${ }^{15)}$

a lotus type porous copper also has been made by using electrodeposition nickel on lotus supper ingot. The ingot was fabricated using a unique casting technique ${ }^{16)}$. Another method is a porous copper material made by 
compacted copper wire ${ }^{17)}$ and sintered part aligned with tensile load to produce straight oriented pore ${ }^{18)}$.

In powder metallurgy, there is a method to form a porous material using starch as the carrying fluid and the consolidator. It is the method to consolidate iron powder using starch ${ }^{19)}$. Water-based processing for metal powder using organic additives was critical regarding the oxygen/carbon content and the consequences for the sintering performance and ultimate material properties. On the other hand, it is found that this method produces fragile molded parts during the demolding process. Therefore, freezing before the demolding was employed to facilitate the demolding process. They had difficulties in removing the trapped air during the mold filling because of the viscosity of the starch solution. A fabrication of High-Speed Steel with high hardness and bending strength could be achieved using starch as a binder ${ }^{19)}$. Starch used as a binder material could be employed in a Metal Injection Molding process ${ }^{20)}$. Starch that had been used as a binder material for metal injection molding process using alumina powder. It was able to produce sintered alumina with dense parts and high mechanical properties ${ }^{21)}$. A starch binder material had been a well-established material with short forming time, high yield, high green product capacity, and it had been used to prepare a porous or solid component with high quality and complex shape ${ }^{22)}$.

A method to determine the capillary performance of the loop heat pipe (LHP) was employed using an electronic balance to measure the displacement of fluid from a container to the wick acting as the porous media in $\mathrm{LHP}^{5}$. The displacement showed an exponential graphic that could be presented as an equation of exponential of which the typical Eq. 1 was:

$$
y=y_{0}+A \cdot e^{-\tau / t}
$$

The literature review showed that a sintered powder configuration for a capillary wick had more advantages than the other two standard capillary wick configurations using wire mesh and capillary grove ${ }^{4)}$. Previous studies also showed that starch used as a binding material could be employed in various applications to fabricate porous materials. We hoped that this study would provide a fabrication method and optimum fabrication parameters in manufacturing an LTP.

\section{Experimental Method}

\subsection{Materials}

a starch is used to bind the copper powder. The starch was mixed with $5 \%$ by weight of hot water to make a cellulose gel. The gel was mixed with copper powder amounting to $55 \%$ by weight to make a slurry. A slip casting technique was adopted to fabricate LTP using copper powder and performer ${ }^{23,24)}$.
A lotus-type porous material mimicked a lotus rod which had a directional and continuous porous structure. To mimic lotus structure, an array of the directional and continuous porous structures are formed by a nylon wire. Fig. 1 shows the schematic of fabrication of the lotus-type porous structure. The nylon wire is coated with copper slurry and placed into a mold. The performer was removed to leave continuous directional pores during the sintering process. in the other hand, inter grain structure was also produced to connect between directional pores.

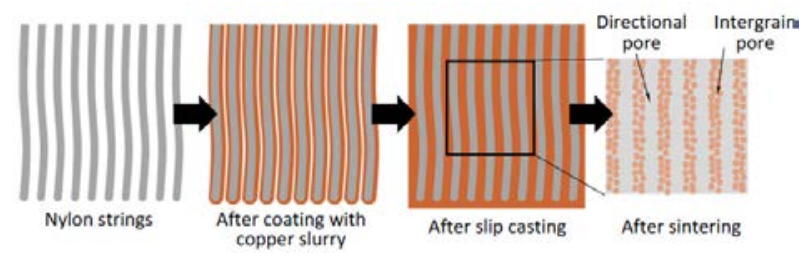

Fig. 1 : Schematic of fabrication of lotus-type porous material ${ }^{21)}$.

Fig. 2 showed a mold setup for the slip casting were (1) was a mold, (2) was screen holder, (3) was a screen mesh to hold the pore-former, (4) mold, (5) was the pore-former, and (6) was the pouring cup to cast the slurry. Fig. 3 shows a schematic procedure to prepare the LTP specimen. After slurry materials were prepared and the mold was set up, as Fig. 2 shows us. The pore-formers were aligned correctly in the mold. Then the slurry material was poured into the mold, as shown in Fig. 2. It was necessary to do the vacuuming to remove the trapped air in the mold after the slurry was poured. The specimen was then dried using freeze-drying to reduce the moisture level and increase the curing rate; therefore, the sample would easily be removed from the mold. The secondary heating process was conducted to remove the excess moisture. The dried specimen was then sintered under the vacuum condition at various temperatures ranging from 800 to $900^{\circ} \mathrm{C}$ for different holding times ranging from 40 to 80 minutes $^{23)}$.

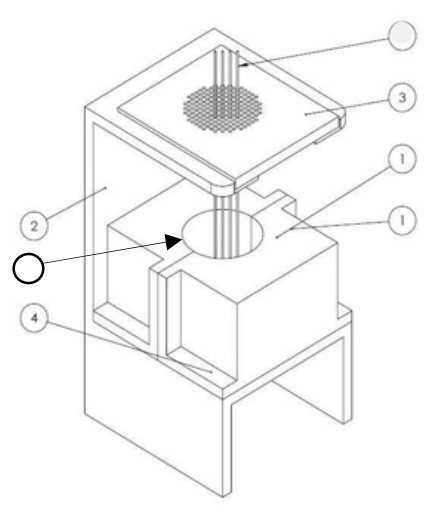




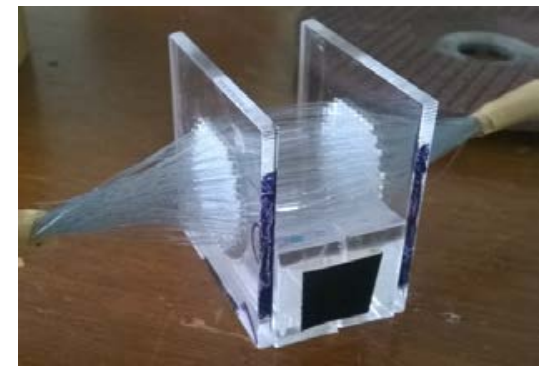

Fig. 2 : Mold setup for a slip casting method.

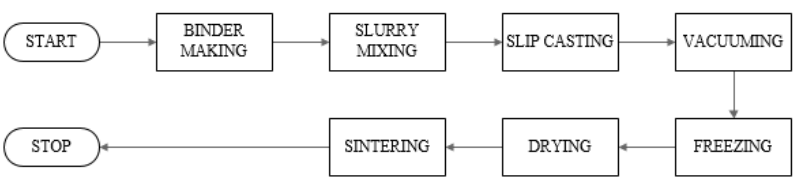

Fig. 3 : Schematic of the manufacturing process.

Taguchi method was employed in this study to observe the effect of Pore Former Size (PFS), Powder Size (PS), Sintering Temperature (TEs), and Sintering Time (TIs) on the capillary performance required in the heat pipe application $^{25,26)}$. Table 1 shows the numbers of specimens under the various levels of the processing conditions.

Table 1 Orthogonal table of specimens under various processing conditions

\begin{tabular}{ccccc}
\multicolumn{5}{c}{ L9 Ortoghonal } \\
\hline Sample & PFS & PS & TEs & TIs \\
\hline 1 & 100 & 100 & 800 & 40 \\
\hline 2 & 100 & 200 & 850 & 60 \\
\hline 3 & 100 & 300 & 900 & 80 \\
\hline 4 & 120 & 100 & 850 & 80 \\
\hline 5 & 120 & 200 & 900 & 40 \\
\hline 6 & 120 & 300 & 800 & 60 \\
\hline 7 & 150 & 100 & 900 & 60 \\
\hline 8 & 150 & 200 & 800 & 80 \\
\hline 9 & 150 & 300 & 850 & 40 \\
\hline
\end{tabular}

The permeability test in this study referred to ASTM D2434 using a static method ${ }^{27)}$. Fig. 4 showed the configuration of the permeability test. In this test, the specimen was placed in a holder. Then, it was drained with water from a higher position. The test was conducted at different heights of the pool (water container). The flow rate of water passing through the specimen is measured.

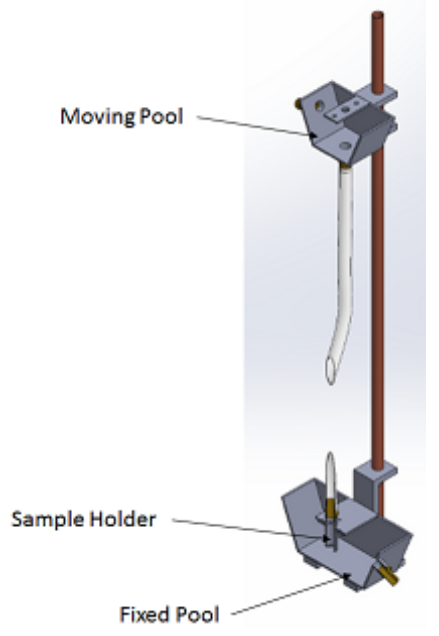

Fig. 4: The permeability test apparatus.

The water flow rate was converted into permeability using Eqs. 2 and 3.

$$
\begin{aligned}
& \kappa=\mu \frac{L}{\Delta p} \frac{Q}{A} \\
& \kappa=K \frac{\mu}{\rho g}
\end{aligned}
$$

Where $\kappa$ was permeability, $Q$ was flow rate, $A$ was cross-sectional area perpendicular to flow, $\mu$ was viscosity, $\nabla p$ was pressure gradient, $L$ was specimen length, and $K$ was hydraulic conductivity.

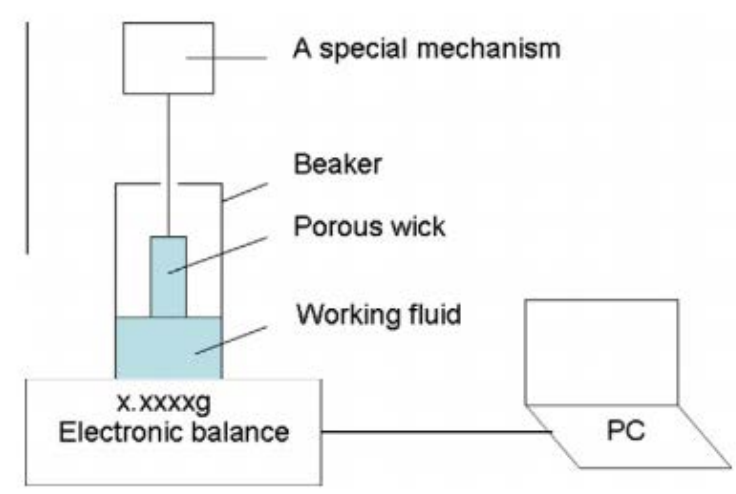

Fig. 5 : Schematic of capillary pumping test $t^{23)}$.

\subsection{Capillary Pumping test}

The capillary pumping performance was measured using a method referring to the capillary pumping amount in real-time changing curve ${ }^{5)}$. The data from this experiment was incremental to the fluid mass due to its capillary pumping from the specimen.

Fig. 4. showed the experimental setup for the capillary pumping test. The specimen was hung into the weight scale, which was recorded by a type-GF-300 data acquisition device $A \& D$. The edge of the sample was 
moved down until its contact with the water. The water would be pumped up due to the capillary force indicated by the increasing weight of the specimen. The capillary pumping rate was calculated using the derivative of the pumping amount ${ }^{4}$.

\section{Results and Discussion}

Capillary pumping rate is the ability to absorb the amount of working fluid per second. A high capillary pumping rate was indicated with a steep curve of capillary pumping; as shown in Fig. 6. The increasing powder size also increased the interconnected of aligned pore size, which increased the capillary pumping rate and the amount of capillary pumping due to the high porosity volume due to its large space between the powder particles.

Table 2 shows summary of permeability and capillary pumping of LTP under given variation. Pore former size at $120 \mu \mathrm{m}$ shows highest capillary pumping performance. This size is able transport fluid effectively. Increasing particle size under given range and lowering sintering temperature also improve capillary pumping. Cappilary pumping performance is strongly directly effect by pore size that vary under particle size, performer size and sintering temperature. While sintering time affect to bonding strength of each particle.

In the other hand, permeability of the wick material proportional to pore former size and particle size. Permeability increase promotional to pore size in all given range.

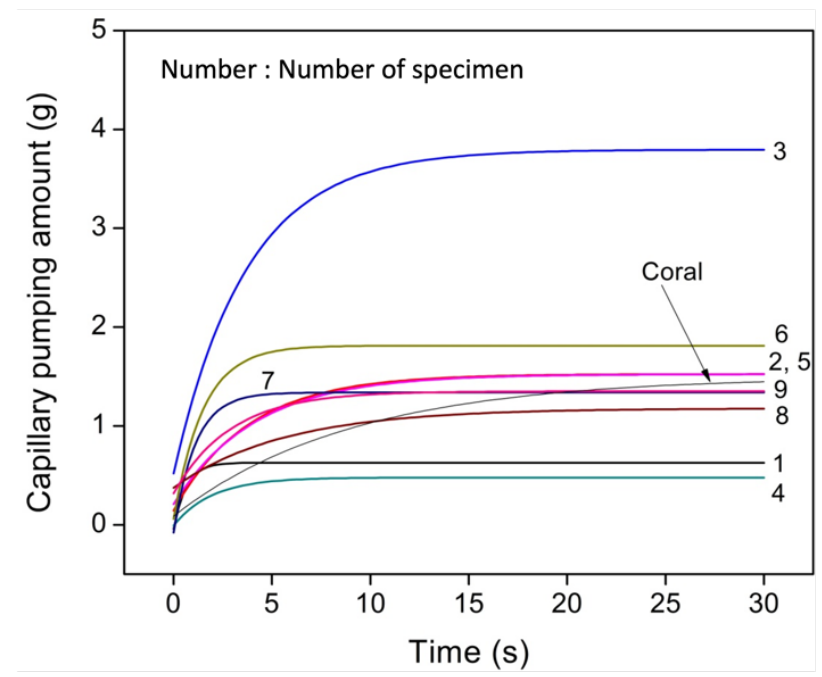

Fig. 6 : The amount of capillary pumping of the specimen number.
Table 2 Capillary pumping rate and permeability

\begin{tabular}{ccc}
\hline Sample & $\begin{array}{c}\text { Capillary Pumping } \\
\text { Rate } \\
\mathbf{( g / s )}\end{array}$ & $\begin{array}{c}\text { Permeability } \\
\left(\mathbf{m}^{\mathbf{2}} \mathbf{)}\right.\end{array}$ \\
\hline Sample 1 & 0.48 & $1.05, \mathrm{E}-10$ \\
\hline Sample 2 & 2.43 & $1.34, \mathrm{E}-09$ \\
\hline Sample 3 & $\mathbf{3 . 2 4}$ & $2.72, \mathrm{E}-09$ \\
\hline Sample 4 & 1.31 & $1.93, \mathrm{E}-10$ \\
\hline Sample 5 & 2.34 & $7.24, \mathrm{E}-10$ \\
\hline Sample 6 & $\mathbf{3 . 9 9}$ & $\mathbf{2 . 6 0 , E - 0 9}$ \\
\hline Sample 7 & 0.96 & $4.37, \mathrm{E}-10$ \\
\hline Sample 8 & 2.88 & $3.83, \mathrm{E}-10$ \\
\hline Sample 9 & 2,45 & $3,24, \mathrm{E}-09$ \\
\hline Coral & 0,17 & $5,88 \mathrm{E}-11$ \\
\hline
\end{tabular}

SEM analysis clarified that sintered LTP has two types of the pore, as shown in Figs. 7 and 8. First, interparticle pore, which forms by the gap between powder particles. Interparticle pore size increase with particle size. Second, aligned pore from pore former. With a bigger particle size more significant pore connection exist in the specimen. Main aligned pore and interconnection pore shown in the SEM analysis explain phenomena in the capillary and peameability test. High capillary and permeability performance of LTP as as wick material of the LTP higher than coral as base line of the previous research.

LPT's high permeability could be observed under an Xray graph analysis as shown in Fig. 9. The pores are straight aligned and continuous pores from the bottom to the top of the specimen. The straight and aligned pores were produced from the pore former. This condition made the fluid easily infiltrate the sample and increased the permeability and capillary pumping rate.
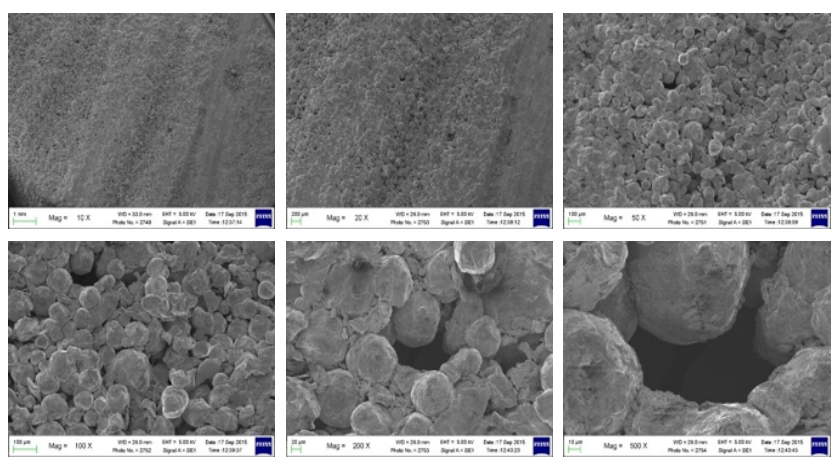

Fig. 7 : Results of the fabrication of copper LTP, with the powder diameter amounting to $100 \mu \mathrm{m}$, the diameter pore former amounting to $120 \mu \mathrm{m}$ 

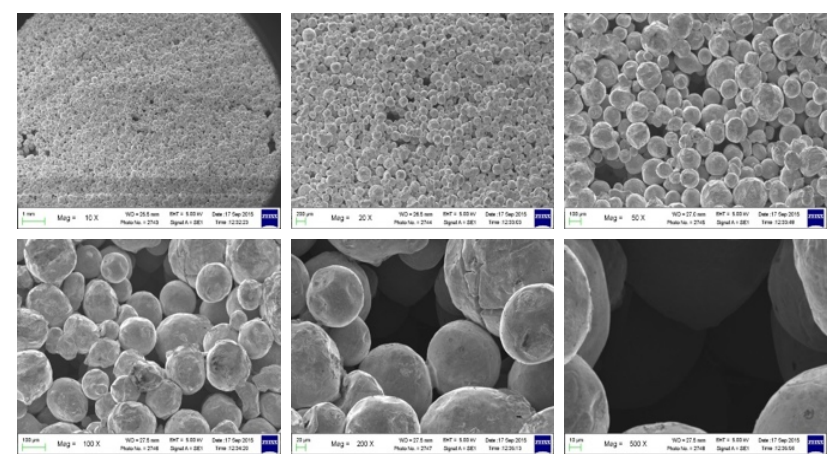

Fig. 8 : Results of the fabrication of copper LTP, with the powder diameter amounting to $200 \mu \mathrm{m}$, the diameter pore former amounting to $120 \mu \mathrm{m}$
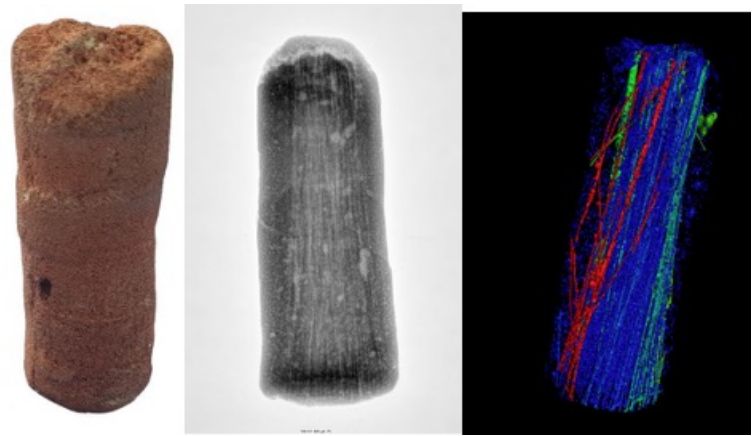

Fig. 9 : Photographs of the LPT of sample number 6, X-ray image, and pore analysis, respectively.

\section{Conclusions}

A new fabrication technique of a material mimicking a lotus stem and exceeding the performance of a coral as the wick material had been successfully demonstrated. A projected Lotus-Type Porous Material (LTP) could outperform a coral, and this study proved it. The lotustype porous material was fabricated with a slip casting process using a starch binder and copper powder. The performance of the lotus-type porous material was characterized to get a capillary pumping coefficient. The pore shape was analyzed using SEM and X-ray 3D Scan showing a straight aligned pore. The results showed that an excellent capillary pumping performance could be achieved using a lotus-type porous material. Further studies have to be conducted in order to enhance the potential of this technique.

\section{Acknowledgments}

This study and its publication were conducted under a research grant by Hibah Publikasi Internasional Terindeks from Universitas Indonesia, 2019.

\section{References}

1) H. Han, M Hatta, and H. Rahman, "Smart Ventilation for Energy Conservation in Buildings,” Evergreen, 6 (1) 44-51( 2019). doi: 10.5109/2321005.
2) S. Hanif, M. Sultan, T. Miyazaki, and S. Koyama, "Steady-state investigation of desiccant drying system for agricultural applications,” Evergreen, 5 (1) 33-42 (2018). doi:10.5109/1929728

3) I. Yaningsih, M.H. Mahmood, A.T. Wijayanta, T. Miyazaki, and S. Koyama, "Experimental study on dehumidification technology using honeycomb desiccant block," Evergreen, 5 (1) 11-18 (2018). doi:10.5109/1936212.

4) N. Putra, R. Saleh, W.N. Septiadi, A. Okta, and Z. Hamid, "Thermal performance of biomaterial wick loop heat pipes with water-base Al2O3 nanofluids,”. Int. J. Therm. Sci., 76 128-136 (2014). doi: 10.1016/j.ijthermalsci.2013.08.020

5) Li, J., Y. Zou, and L. Cheng, "Experimental study on capillary pumping performance of porous wick for loop heat pipe,” Exp. Therm. Fluid. Sci., 34 (8) 14031408 doi:10.1016/j.expthermflusci.2010.06.016.

6) N. Putra and W.N. Septiadi, "Improvement of heat pipe performance through integration of a coral biomaterial wick structure into the heat pipe of a CPU cooling system,” Heat Mass Trans., 53 (4), 1163-1174 (2017). doi: 10.1007/s00231-016-1890-6.

7) R. Sureshkumar, S. Tharves Mohideen, and N. Nethaji, "Heat transfer characteristics of nanofluids in heat pipes: A review,” Renew. and Sustain. Energy Rev., $20 \quad 397-410 \quad$ (2013). doi: 10.1016/j.rser.2012.11.044.

8) S.F. Li, Y.Y. Bao, P.Y. Wang, and Zhen. Liu. "Effect of nano-structure coating on thermal performance of thermosyphon boiling in microchannels,” Int. J of Heat Mass Transf. 124 463-474 (2018). doi: 10.1016/j.ijheatmasstransfer.2018.03.07.

9) W.N. Septiadi, K. Astawa, A.G.A.P Avrikadewi, D Febraldo, and G.J.P Putra,” Boiling Phenomenon of Graphene Nano-Coating Wick Heat Pipe“. Evergreen, 7 (2) 297-302 (2020). doi: 10.5109/4055236.

10) Y. Gunawan, N. Putra, E. Kusrini, I.I. Hakim, and M.D.H. Setiawan, "Study of Heat Pipe Utilizing Low-Temperature Geothermal Energy and Zeolite-A for Tea Leaves Withering Process,” Evergreen, 7 (2) 221-227 (2020). doi: 10.5109/4055223.

11) B Ariantara, N Putra, and S Supriadi, "Battery thermal management system using loop heat pipe with LTP copper capillary wick” J. Phys. Conf. Ser., 105 (1) (2017). doi: 10.1088/17551315/105/1/012045.

12) G. Kumaresan, S. Venkatachalapathy, L.G. Asirvatham, and S. Wongwises, "Comparative study on heat transfer characteristics of sintered and mesh wick heat pipes using $\mathrm{CuO}$ nanofluids”. Int. Commun. Heat. Mass. 57 208-215 (2014). doi: 10.1016/j.icheatmasstransfer.2014.08.001.

13) M.K Russel, C. Young, J.S. Cotton, and C.Y. Ching, "The effect of orientation on U-shaped grooved and sintered wick heat pipes,”. App. Therm. Eng. 31 (1) 

69-76
(2011).
doi:

10.1016/j.applthermaleng.2010.08.013.

14) M. Fink, O Andersenn, T. Seidel, and A. Schlott, "Strongly Orthotropic Open Cell Porous Metal Structures for Heat Transfer Applications,”. Metals, 8 554 (2018). doi: 10.3390/met8070554.

15) Y. Ma, C.L Huang, and X.D Wang, "Experimental investigation on boiling heat transfer enhanced by gradient aperture porous copper”, App. Therm. Eng. $191 \quad 116877$ (2021). doi: 10.1016/j.applthermaleng.2021.116877.

16) S.K. Hyun, and H. Nakajima, "Effect of solidification velocity on pore morphology of lotus-type porous copper fabricated by unidirectional solidification," Mater. Lett. 57 3149-3154 (2003). doi: 10.1016/S0167-577X(03)00012-0.

17) O. Andersen, J. Meinert, T. Studnitzky, G. Stephani, and B. Kieback, "Highly heat conductive openporous aluminium fibre based parts for advanced heat transfer applications” Materiawiss. Werkstofftech. 43 328-333 (2012). doi: 10.1002/mawe.201200949.

18) B.Liu, X.G Wang, Y. Tang, W. Yuan, C.B Fang, and Z.P Wan,"Experimental Study on the Tensile Property of a Novel Oriented Linear Porous Metal,” Adv. Mater. Sci. Eng. 12 1-8 (2016). doi: 10.1155/2016/3930703.

19) P.R. Tiguero, O. Lyckfeldtm, and W. Khraisat, "Water-based processing of iron powder utilizing starch consolidation,” Powder Metall., 48 (2) 156162 (2005). doi:10.1179/003258905X37576.

20) P.R. Tiguero., F.J. Velasco, and J.M. Torralba, "Starch Consolidation as a New Process for Manufacturing Powder Metallurgy High-Speed Steels,” Metall. Mater. Trans., $38 \quad$ (1) 159-168 (2007). doi:10.1007/s11661-006-9037-x.

21) H. Abolhasani, and N. Muhamad, “A new starchbased binder for metal injection molding,” J. Mater. Process. Technol., 210 (6) 961-968. (2010). doi: 10.1016/j.jmatprotec.2010.02.008.

22) J. Chandradassa, K. H. Kim, D. S. Bae, K. Prasad, G. Balachandar, S. A. Divya, and M. Balasubramanian, "Starch consolidation of alumina: Fabrication and mechanical properties,” J Eur. Ceram Soc., 29 (11) 2219-2224 (2009). doi: 10.1016/j.jeurceramsoc.2009.02.001.

23) J. Yang, J. Yu, and Y. Huang, "Recent developments in gelcasting of ceramics,” J. Eur. Ceram. Soc. 31 (14) 2569-2591 (2011). doi: 10.1016/j.jeurceramsoc.2010.12.035.

24) S. Supriadi, N. Putra, B. Ariantara, Sunaryo, and D.D. Rahmanto, "Fabrication of Lotus-Type Porous Copper Using Slip Casting and Sintering Techniques for Heat Pipe Applications,” Appl. Mech. Mater, 819 601-605 (2016). doi: 10.4028/www.scientific.net/AMM.819.601.

25) G. Taguchi, and Y. Yokoyama, "Taguchi methods: design of experiments”. 1993: ASI Press.
26) G.S.Peace, “Taguchi methods: a hands-on approach”, Addison-Wesley, 1993

27) D2434-68(2006), A., Standard Test Method for Permeability of Granular Soils (Constant Head) (Withdrawn 2015). 2006, West Conshohocken: ASTM International. 